\title{
Avaliação do Plano Operacional de Comercialização do Turismo: o caso de Bonito, município de Mato Grosso do Sul - Brasil
}

\author{
Evaluation of Operational Plan of Tourism Marketing: the case of Bonito, city of Mato \\ Grosso do Sul - Brazil
}

\section{Evaluación del Plan Operativo de Marketing de Turismo: el caso de la municipalidad de Bonito, en Mato Grosso do Sul - Brasil}

\author{
Mariana Monfort Barboza ${ }^{1}$ \\ Dyego de Oliveira Arruda ${ }^{2}$ \\ Milton Augusto Pasquotto Mariani ${ }^{3}$
}

\section{Resumo}

O presente estudo tem como objetivo geral analisar as percepções do trade turístico de Bonito acerca do plano de comercialização desenvolvido para o município, buscando a compreensão da interface marketing-turismo. Tratando-se o marketing turístico como uma ferramenta para a conquista e manutenção de clientes, a fim de que a experiência vivenciada pelo turista seja única e inesquecível, o presente estudo justifica-se na busca de contribuições para a gestão pública do destino turístico analisado, com vistas a sua consolidação como pólo na atração de visitantes. Trata-se de um estudo qualitativo, de natureza exploratória, descritiva e explicativa, cujo procedimento de coleta, análise e interpretação dos dados resumiu-se em entrevistas com os atores locais. Os resultados apontam que aproximadamente $89 \%$ dos sujeitos consideram o plano importante para o desenvolvimento da atividade turística local, sendo que $44 \%$ o consideram importante para "vender" o destino como ícone brasileiro no ecoturismo; $33 \%$ o consideram importante por propiciar o direcionamento da região rumo à atração de turistas do mundo todo e $11 \%$ o consideram importante como ação estratégica para superar as dificuldades existentes e construir um novo posicionamento estratégico no mercado turístico. Sendo assim, referindo-se ao turismo como um dos principais setores empregatícios e gerador de renda para o município, o plano de comercialização se apresenta como uma ferramenta importante para a consolidação do destino como um verdadeiro pólo na atração de turistas.

Palavras-chave: turismo; marketing; marketing turístico.

\footnotetext{
${ }^{1}$ Graduada em Administração pela Universidade Federal de Mato Grosso do Sul (UFMS). Mestranda em Administração pela Universidade Federal do Paraná (UFPR), bolsista da Coordenação de Aperfeiçoamento de Pessoal de Nível Superior (Capes). E-mail: marianamonfort@gmail.com.

${ }^{2}$ Discente do curso de Ciências Econômicas do Departamento de Economia e Administração da Universidade Federal de Mato Grosso do Sul (DEA/UFMS). Atualmente, é bolsista de Iniciação Científica do Conselho Nacional de Desenvolvimento Científico e Tecnológico (CNPq). E-mail: dyego.arruda@gmail.com.

${ }^{3}$ Geógrafo pela Universidade Estadual Paulista Julio de Mesquita Filho (UNESP). Mestre em História Social pela Pontifícia Universidade Católica de São Paulo (PUC-SP). Doutor em Geografia Humana pela Universidade de São Paulo (USP). Professor dos cursos de Ciências Econômicas e Administração; e do Programa de Mestrado em Administração, do Departamento de Economia e Administração da Universidade Federal de Mato Grosso do Sul - DEA/UFMS. E-mail: miltmari@terra.com.br.
} 


\begin{abstract}
This study has as general goal evaluate Bonito's tourist trade perceptions concerning the marketing plan developed for the city, seeking for understanding the marketing-tourism interface. Considering the touristic marketing as a tool for the achievement and maintenance of costumers, so that the experience is unique and unforgettable, this study is justified in seeking contribution for public management of the destination, aiming to consolidate its position as national and international tourist hub. This is a qualitative study, of exploratory, descriptive and explanatory nature, whose procedure for collection, analysis and interpretation of data was based on interview with local people. The results show that $89 \%$ of the people consider the plan important for the development of local tourist activity, 44\% considering it important to "sell" the destination as Brazilian icon in ecotourism, 33\% considering it important to propitiate the directioning of the region toward the attraction of tourist from all over the world, and 11\% considering it important as strategic action to surpass existing difficulties and make a new strategic positioning in tourism market. So being, showing the tourism as a main employer sector and income generator for the city, the marketing plan is presented as an important tool to consolidate this destiny as a national and internacional tourist hub.
\end{abstract}

Keywords: tourism; marketing; touristic marketing.

\title{
Resumen
}

El presente estudio tiene como objetivo general analizar la percepción del trade turístico sobre el plan de marketing desarrollado para la ciudad de Bonito, en Mato Grosso do Sul/Brasil, tratando de entender la relación que hay entre el marketing y el turismo. En cuanto a la promoción del turismo como una herramienta para obtener y mantener clientes, por lo que la experiencia turística es única e inolvidable, este estudio se justifica en la búsqueda de aportes para la gestión pública de los destinos turísticos, con miras a su consolidación como centro turístico nacional e internacional. Se trata de un estudio cualitativo, exploratorio, descriptivo y explicativo, cuyo procedimiento para la recolección, análisis e interpretación de datos, se realizaron entrevistas con los actores locales. Los resultados muestran que aproximadamente el $89 \%$ de los temas importantes a considerar el plan de desarrollo del turismo local, y el 44\% consideran que es importante para "vender" el destino como icono de Brasil en el ecoturismo, el 33\% considera que es importante porque proporciona la dirección de región hacia la atracción de turistas de todo el mundo y el 11\% consideran que es importante como una estrategia para superar las dificultades y construir un nuevo posicionamiento estratégico en el mercado turístico. Así, en referencia al turismo como un empleado de los principales sectores y generador de ingresos para la ciudad, el plan de marketing se presenta como una herramienta importante para la consolidación del destino como atractivo turístico nacional e internacional.

Palabras clave: turismo; marketing; marketing turístico. 


\section{Introdução}

Globalização, transformações econômicas, políticas e sociais, período de mudanças rápidas e inesperadas, é assim que podemos definir o novo cenário mundial característico do século XXI. Neste quadro, marcadamente dinâmico; calcado no intenso fluxo de renda, pessoas e na constante inter-relação pessoas-lugares, uma atividade ganha notório destaque: o turismo.

Dado o seu papel relevante no desenvolvimento socioeconômico de diversas localidades, na geração de renda econômica e na constituição de empregos diretos e indiretos em virtude de seu considerável efeito multiplicador da receita gerada, o turismo mostra-se como uma atividade que vem ganhando destaque em todo o mundo. Segundo Almeida (2002: 18) o turismo é tão pujante em princípios do século XXI que “(...) segundo previsões feitas por especialistas e organismos de turismo, ele se constituirá na primeira atividade mundial em termos de receita e no maior empregador de mão-de-obra".

Rememorando dados da Organização Mundial de Turismo (World Tourism Organization WTO, 2009), a contribuição do turismo para o crescimento do Produto Interno Bruto (PIB) do mundo é estimada em cerca de 5\%. Somente no ano de 2008, as viagens internacionais movimentaram um total de 922 milhões de turistas, gerando uma renda de aproximadamente US\$ 5 trilhões; valores estes que sofreram quedas no ano de 2009 diante do estabelecimento de um quadro de crise econômica mundial, com perspectivas de crescimento para o ano de 2010, em números próximos a 935 milhões de turistas em todo o mundo diante do aparente restabelecimento da economia global (WTO, 2010).

No Brasil, seguindo mesma tendência de recuperação da atividade turística, dados do Banco Central mostram que a receita cambial gerada pelos gastos de turistas estrangeiros no país atingiu US\$ 2,9 bilhões de janeiro a junho de 2010; valores 14,5\% superiores aos obtidos no mesmo período do ano imediatamente anterior (ETENE, 2010). Quanto à geração de empregos, o Instituto Brasileiro de Geografia e Estatística (IBGE, 2005) dá conta de que, no ano de 2005, as Atividades Características do Turismo (ACT) geraram 8,92\% do total de vagas de trabalho existentes na economia daquele ano; valores que apresentam, pois, 
tendência de alta nos anos mais recentes, sobretudo por conta das conjunturas econômicas brasileiras favoráveis.

Diante do contexto contemporâneo de tomada de importância do turismo como mecanismo cada vez mais relevante na geração de empregos e renda econômica, surgem as várias iniciativas de fomento a esta atividade como um todo; bem como aos destinos turísticos, em particular. Nesse ínterim, nota-se que o marketing é tomado como ferramenta estratégica relevante na venda dos produtos turísticos e no entendimento de necessidades da demanda por parte dos potenciais consumidores de tais produtos.

Santana (2008: 427) lembra que os instrumentos de marketing de destinos turísticos resumemse na divulgação de produtos singulares, que possuem “(...) tanto uma experiência única, como também uma vasta gama de atributos como belezas naturais, alto valor utilitário, clima, localização geográfica, qualidade das facilidades e serviços, hospitalidade, segurança, história, costumes locais e comércio, dentre outros atributos". Pressupõe-se, mesmo que o produto turístico seja interpretado como sendo massificado e/ou estereotipado, a identificação de necessidades de consumo nos potenciais turistas, incrementando suas expectativas quanto à possibilidade de visita no destino.

Alguns estudos consagrados, dentre os quais pode-se citar Ruschmann (1995); Vaz (1999); Kuazaqui (2000); Mota (2001); Middleton (2001, 2002); Balanzá e Nadal (2003); Petrocchi (2004); Dias e Cassar (2005), testam a importância e, por conseguinte, a necessidade de novas pesquisas acerca da interface entre marketing e turismo.

Um caso prático de aplicação das ferramentas de marketing ao fomento do turismo pode ser identificado no município de Bonito, no estado de Mato Grosso do Sul. Localizado estrategicamente no corredor ecoturístico brasileiro que resulta de uma articulação entre os estados do Pará, Amazonas, Mato Grosso, Mato Grosso do Sul e Paraná, Bonito é uma das principais portas de entrada do pantanal sul-mato-grossense, com uma grande quantidade e diversidade de atrativos naturais, consolidando-se nos anos recentes como um dos principais pólos indutores do ecoturismo nacional. 
Segundo dados oficiais disponibilizados pelo poder público de Bonito, desde o surgimento da atividade turística no município, em 1993, o número de turistas que visitam a cidade apresentou reiterados aumentos, quando, em 2003, nota-se uma queda no número de visitantes, seguida de igual declínio nos anos de 2004 e 2005, o que exigiu do poder públicoprivado local o estabelecimento de ações mercadológicas que fizessem frente às dificuldades de comercialização do destino. Nesse contexto, surge no ano de 2006 o Plano Operacional de Comercialização do Destino Bonito-MS (neste território em análise este instrumento é denominado como Plano de Marketing), visando ao estabelecimento de ações emergenciais e de ordem estratégica, com o fito de alçar Bonito a um novo posicionamento estratégico no mercado turístico nacional (PREFEITURA MUNICIPAL DE BONITO, 2006).

Porém, qual a visão do trade turístico local acerca das ações pactuadas no Plano de Comercialização de Bonito? É uma indagação que permite o estabelecimento de reflexões acerca das possíveis sinergias existentes no desenrolar das estratégias do Plano, o que por si só pode fornecer subsídios que permitam inferir sobre a possível efetividade e importância do Plano de Comercialização em questão.

Sendo assim, dadas estas considerações preliminares, o presente trabalho tem como objetivo geral analisar as percepções do trade turístico de Bonito acerca do Plano de Comercialização desenvolvido para o município. Dada a constatação da escassez de estudos e pesquisas acerca da temática em voga, acredita-se que a abordagem por ora proposta tem certo pioneirismo no Brasil, mais precisamente em Mato Grosso do Sul, de forma que os resultados obtidos venham a contribuir para outras iniciativas de pesquisa, assim como gerar alguma contribuição objetiva para o sucesso do destino turístico de Bonito, frente ao mercado nacional e internacional de turismo.

Em suma, o trabalho está estruturado em quatro partes, além desta introdução e da conclusão. $\mathrm{Na}$ primeira parte, apresenta-se uma síntese acerca do 'estado da arte' do turismo, suas principais definições, além da tônica da atividade turística no município de Bonito, locus da presente análise. Na segunda parte, descrevem-se algumas definições aventadas acerca do marketing como campo de análise científica, correlacionando-o aos contextos de análise do 
turismo; bem como ao caso de Bonito. Na terceira parte elucidam-se os procedimentos metodológicos que embasaram a pesquisa, ao passo que, na quarta e última parte, sintetizamse os resultados levantados.

\section{Turismo: breves notas conceituais}

Para entender a amplitude do turismo, sua complexidade e carência de definições universais, faz-se necessário rememorar a origem de um fenômeno que não é novo. Lage e Milone (1998) entendem que o surgimento do turismo remonta a períodos distantes, como o da Antiga Babilônia, da Grécia, de Roma e de outros impérios da Idade Média, quando surgiram as primeiras viagens. Com a decadência do Império Romano e a invasão dos bárbaros, no século IV, os deslocamentos humanos foram reduzidos, tendo o seu ressurgimento marcado pelo período do Renascimento, onde "surgiram muitas viagens de artistas, de artesãos, de músicos, de poetas, representando um grande incentivo à atividade de deslocamento" (LAGE; MILONE, 1998: 15-16).

Um novo marco importante na história do turismo foi o advento da Revolução Industrial, na segunda metade do século XVIII e primeira metade do século XIX. Neste período nota-se o surgimento de uma classe média ávida por novos gastos direcionados à ocupação de seu tempo livre (LAGE; MILONE, 1998).

Os primeiros esforços em definir o turismo o tratavam como um deslocamento de turistas, que reunia certas características específicas, como a duração e a motivação da viagem, o que não diverge muito das definições atuais. Para a Organização Mundial do Turismo (OMT, 2003: 20), “o turismo são as atividades de pessoas que viajam para lugares afastados de seu ambiente usual, ou que neles permaneçam por menos de um ano consecutivo, a lazer, a negócios ou por outros motivos". 
De acordo com Andrade (1998:38), "turismo é o conjunto de serviços que tem por objetivo o planejamento, a promoção e a execução de viagens, e os serviços de recepção, hospedagem e atendimento aos indivíduos e aos grupos, fora de suas residências habituais”.

Para Droulers e Milani (2002), um produto turístico busca satisfazer as motivações e expectativas (nota-se aqui o conceito de "marketing" que será posteriormente discutido) relacionadas com o tempo livre dos turistas. Sendo a soma de componentes tangíveis e intangíveis, tais como, recursos e atrativos naturais, equipamentos e infraestruturas, serviços, atitudes recreativas, imagens e valores simbólicos.

O turismo apresenta três limitações estruturais, que auxiliam em sua caracterização: a transitoriedade, pois há uma relação diretamente proporcional entre a perda de atratividade do destino, o uso de técnicas gerenciais falhas, os problemas de instabilidade política e insegurança, como também, a dificuldade de acesso versus o declínio da região turística; a sazonalidade, decorrente da concentração da demanda em um curto período de tempo; e a polarização no espaço, conseqüência da sazonalidade, que corresponde a uma alta densidade de ocupação territorial, em um curto período de tempo (DROULERS; MILANI, 2002; COOPER et al, 2007).

As necessidades da demanda turística não são mais basicamente individuais, mas surgem das necessidades coletivas, dos novos modos de vida das pessoas. A novidade do turismo situa-se no lugar que na vida das pessoas, progressivamente conquistado em virtude da proliferação de pacotes turísticos, que "proporcionam a possibilidade de viajar a quase todas as pessoas dos países industrializados, tornando-se, cada vez mais, uma reivindicação e um direito do homem civilizado" (RUSCHMANN, 1995:13).

O progresso econômico, a concentração urbana, as facilidades de acesso, circulação e desenvolvimento dos transportes, contribuíram para a expansão do turismo, o tornando objeto de atenção dos governos por sua importância indubitável para a realidade socioeconômica (RUSCHMANN, 1995; MIDDLETON, 2002). 
O incentivo a atividade turística não significa torná-la única fonte geradora de riquezas para os destinos, e sim, mais uma opção econômica que alavanque e fortaleça todas as outras atividades econômicas, como a agricultura, a pecuária, o comércio, o artesanato, a indústria de serviços, dentre outras (CORIOLANO, 2002).

Desta, fica patente a importância do turismo no contexto socioeconômico das localidades onde tal atividade é empreendida. Sendo assim, nota-se a necessidade de se pensar estratégias (sobretudo calcadas nas ferramentas de marketing) que tenham como escopo o fomento do turismo - galgando, indiretamente, todos os bônus decorrentes do impulso da atividade turística.

\subsection{O turismo em Bonito/MS}

O Estado de Mato Grosso do Sul é composto por 78 municípios dentre os quais se destaca o município de Bonito, localizado na microrregião geográfica de Bodoquena, no sudoeste do referido estado. Referência nacional em modelo de gestão ambiental e turística, Bonito é vencedora oito anos consecutivos (de 2002 a 2009) do prêmio de 'Melhor destino de ecoturismo do Brasil'; assim como do prêmio 'Top de turismo em 2007' pelo 'Melhor modelo de gestão ambiental e turística do Brasil - voucher único'; Prêmio UPIS de turismo 2008, das Faculdades Integradas de Brasília/DF, de 'Melhor turismo receptivo'; Prêmio do Instituto Ambiental Biosfera de 'Município-Modelo na preservação de áreas verdes e unidades de conservação em 2009'. Premiações que expressam a importância do município frente ao mercado nacional/internacional do turismo.

O município de Bonito foi criado em 1915, com uma vocação para atividades agrícolas e de mineração. Contudo, sua vocação turística só foi assumida em meados da década de 1970, época em que ocorria o chamado 'turismo gratuito'. Os visitantes eram principalmente estudantes de Campo Grande e de outras regiões do interior do Estado (ATRATUR, 2010). 
Segundo Mendonça (2006), antes do surgimento da atividade turística em Bonito, o comércio da região era voltado apenas para o atendimento das necessidades básicas da população. Sendo assim, a partir da década de 1980 com a inclusão do turismo como atividade geradora de emprego e renda para o município, surgem novas necessidades de produtos e serviços, o que leva ao aprimoramento do comércio da região, beneficiando principalmente a comunidade local.

O comportamento do fluxo de turistas de Bonito teve sua ascensão a partir do ano de 1993, com a exibição de um documentário sobre a região de Bonito em rede nacional. Esta mídia espontânea "surpreendentemente" atraiu centenas de pessoas que passaram a procurar a cidade como um "Destino Turístico" Nacional. Surgem então as primeiras iniciativas em relação à estruturação, organização e profissionalização do turismo em Bonito e cria-se o voucher único, principal instrumento de viabilização da atividade turística (MENDONÇA, 2006; PREFEITURA MUNICIPAL DE BONITO et al, 2006; VIGNATI, 2008).

O fluxo de turistas em Bonito, que despertou interesse dos turistas desde 1993, esteve em ascensão até o ano de 2003. O primeiro ano em que o município apresentou números oficiais de turistas, de acordo com dados de sua Prefeitura Municipal, foi em 1996, onde registrou um total de 107.518 turistas. Houve uma queda, a partir de 2003, de 2,25\% em 2004, seguindo em queda $1,20 \%$ no ano de 2005 e 9,83 \% no ano de 2006, configurando assim três anos consecutivos em queda (ISSQN-BONITO, entre 1996 e 2010).

Com este declínio da atividade turística em Bonito, nos anos de 2004 a 2006, segundo informações do Serviço Brasileiro de Apoio às Micro e Pequenas Empresas (SEBRAE), o município perdeu cerca de $24 \%$ de sua atividade turística, enquanto o turismo no Brasil cresceu na mesma proporção (SEBRAE, 2006).

Frente a este declínio, identificou-se um destino com dificuldades de comercialização e atratividade regular de fluxo turístico, fatores importantes para manutenção da capacidade empresarial instalada e dos níveis de emprego e renda do referido município. Sendo assim, houve a necessidade de elaboração de um Plano Operacional de Comercialização do destino 
Bonito-MS, neste território conhecido como plano de marketing, visando ao estabelecimento de ações emergenciais e de ordem estratégica, para a superação das dificuldades existentes e a construção de um novo posicionamento estratégico no mercado turístico (PREFEITURA MUNICIPAL DE BONITO et al, 2006).

Nos tempos de globalização, as empresas bem-sucedidas apresentam cada vez mais o foco em um ponto comum: o fato de serem voltadas para o cliente e profundamente comprometidas com a ferramenta do marketing. Daí denota-se, pois, a importância de tal ferramenta na gestão de negócio (dentre os quais, tem-se aqueles relacionados ao setor de turismo).

\section{Marketing: algumas definições}

O consumidor é o centro do mundo; satisfazer suas necessidades e desejos, reais e potenciais é a chave para a equação dos negócios (KEITH, 1960). Os negócios que não investirem seu máximo esforço para fazer o conceito de marketing funcionar, em breve, ficarão para trás (FELTON, 1959).

O marketing é uma arte; a arte de administrar relacionamentos lucrativos com os clientes, criando valor superior para os consumidores e buscando captar valor do cliente "em troca" (KOTLER; ARMSTRONG, 2007). Para a American Marketing Association (AMA, 2007), o marketing é uma atividade, um conjunto de instituições e processos para criar, comunicar, ofertar e entregar valor para os clientes, parceiros e a sociedade em geral. Muito mais do que a modernização de técnicas de venda o marketing é um conceito voltado para o consumidor, na busca pela adaptação dos produtos e serviços e na satisfação plena das necessidades e desejos dos mesmos.

As variáveis internas que podem ser manipuladas pela empresa para criar valor para o cliente são usualmente conhecidas como os 4P's do marketing, quais sejam: produto, preço, praça e promoção. É através de cada uma dessas variáveis que a empresa se comunica com seus clientes, entregando valor através de bens e serviços (CHURCHILL; PETER, 2007). 
"O marketing se insere nessa seara de conceitos ao desempenhar seu papel na organização, formulando e implementando estratégias" (TOALDO; LUCE, 2006: 27). "O planejamento de marketing implica decidir quais estratégias de marketing ajudarão a empresa a atingir seus objetivos estratégicos gerais”. Logo, faz-se necessário um plano de marketing detalhado para cada negócio, produto ou marca (KOTLER; ARMSTRONG, 2007: 44).

Para Westwood (1991: 05), o plano de marketing é como um mapa que combina todos os elementos do composto mercadológico, estabelecendo onde a empresa está indo e como chegar até lá. É "tanto um plano de ação como um documento escrito [...] e deve identificar as oportunidades de negócios mais promissoras para a empresa e esboçar como inserir, conquistar e manter posições em mercados identificados". O papel do plano de marketing é justamente o de orientar os esforços de marketing de uma organização, de modo a fundamentar todos os objetivos e estratégias a serem fixadas (DIAS \& CASSAR, 2005; VAZ, 1999).

De acordo com Las Casas (1997: 274), "um plano de marketing vem a ser, portanto, a parte escrita do planejamento. É o documento que contêm todos os detalhes para a ação a ser desenvolvida pelos administradores responsáveis”. Ferrell et al (1998) complementa esse conceito; para ele o plano de marketing é um relatório ou documento que aborda as informações que foram descobertas no processo de planejamento, e mais, são os resultados das análises do ambiente da empresa, suas metas, objetivos e elementos chaves das estratégias de marketing.

É inegável a importância da atividade turística para a geração de emprego e renda, e conseqüentemente a movimentação da economia, logo, faz-se indispensável prover ferramentas que estimulem a atividade turística e gerem ações eficazes de "venda" dos destinos. Deste modo, o marketing turístico nasce como uma indubitável força de comercialização dos destinos turísticos.

\subsection{Marketing aplicado a contextos turísticos}

As técnicas mercadológicas para o turismo, apesar de amplamente estudadas na Europa e nos EUA, no Brasil ainda são incipientes, constatação essa que levanta a importância da reflexão 
e do debate deste tema tão importante para a comercialização dos produtos turísticos. O produto turístico é intangível e a experiência vivencial, proporcionada pelas singularidades do produto, fazem com que sua comercialização necessite de técnicas mercadológicas específicas - as do marketing turístico (RUSCHMANN, 1995; QUIAN, 2010).

“As ações mercadológicas do turismo acompanharam a evolução do fenômeno nas últimas décadas. Sempre, porém, se situaram nos conceitos de marketing tradicional - o dos bens tangíveis" (RUSCHMANN, 1995: 21). Porém, "frente a um mercado turístico competitivo, segmentado e instável, o marketing tem ganhado cada vez mais importância para as empresas que prestam serviços turísticos [...] e para o setor terciário em geral”, a importância do estudo do marketing turístico se resume pelo fato de ser um produto intangível cujo principal resultado é a experiência vivenciada pela viagem (LOHMANN; NETTO, 2008: 151).

Na década de 1970 as ofertas do turismo brasileiro eram basicamente de "praia e sol". Contudo, com a capacidade de comunicação global, cada vez mais se desenvolveram destinos com ofertas mais variadas, diversificadas e de alto valor agregado. Diante deste cenário, técnicas de marketing turístico vêm sendo utilizadas para desenvolver estratégias comerciais que aumentem a capacidade de atração dos destinos turísticos (MIDDLETON, 2002; VIGNATI, 2008).

Tornou-se um mantra no mundo dos negócios que a retenção e a lealdade dos consumidores são pontos críticos para o sucesso e que a repetição da compra ou da aquisição dos serviços turísticos, objeto deste estudo, são as chaves para a lucratividade da empresa. É um desafio, do segmento turístico, atrair o consumidor para uma mesma experiência: a repetição de destinos visitados (LITVIN, 2007).

Para Balanzá e Nadal (2003: 41), o marketing turístico corresponde a um "conjunto de técnicas aplicadas pelas empresas turísticas para a comercialização e distribuição dos produtos e serviços para satisfazer as necessidades dos diferentes grupos de consumidores e obter lucro”. Ainda para Petrocchi (2004), o marketing turístico trata da conquista e manutenção dos clientes, de forma que ao fim da experiência vivenciada o turista possa sentir que suas necessidades e desejos foram atendidos, dando uma avaliação favorável ao destino e tencionando voltar. 
O marketing turístico é uma adaptação dos princípios básicos que há tento tempo vem sendo desenvolvidos e praticados em uma vasta gama de produtos para os consumidores, é um processo de troca entre os produtores e os consumidores com vistas a um conjunto coordenado de alavancas ou ferramentas destinadas a corresponder a oferta de produtos às demandas atuais e futuras (MIDDLETON, 2001; 2002).

Segundo Quian (2010), o marketing turístico objetiva estabelecer ferramentas para que os potenciais turistas do mercado-alvo escolham certa região como destino turístico. Fatores potenciais que impactam no marketing do turismo regional incluem: atração turística desenvolvida pelas regiões, maior infraestrutura de apoio à atração turística, o grau de proximidade com a fonte, mercado-alvo, nível de serviço, hospitalidade local e prosperidade econômica.

Para Balanzá e Nadal (2003), o marketing turístico depende de muitas variáveis externas macroeconômicas, políticas, sociais e até históricas, do que os outros setores. Lembrando que diferentemente das estratégias de marketing adotadas pela indústria de serviços, o turismo tem suas particularidades, principalmente quando se referem aos investimentos feitos pelo setor público e privado. Diferentemente do setor de serviços, no qual investimentos isolados do setor privado levam a resultados positivos, no setor turístico, o turista consome toda a "cadeia" do destino, inclusive os serviços públicos, de modo que estes precisam se preocupar com a participação nos investimentos em ferramentas mercadológicas (DIAS; CASSAR, 2005; QUIAN, 2010).

Modernos planos mercadológicos, avançadas técnicas de vendas ou publicidades agressivas não podem esquecer que o objeto principal delas são os turistas, aqueles que imaginaram suas férias durante todo um ano, que sonharam com a experiência a ser vivenciada; "o melhor divulgador de um produto turístico é um cliente satisfeito com as experiências vividas durante sua viagem" (RUSCHMANN, 1995: 25). E para satisfazer as necessidades dos turistas faz-se necessária a definição de estratégias de marketing eficientes.

Para Petrocchi (2004) o turismo no Brasil ainda sofre com a "miopia em marketing", onde o foco nos lucros a curto prazo levam a expansão desordenada dos destinos turísticos, à falta de qualidade na prestação dos serviços causada pelo desprezo na atenção das necessidades e desejos 
dos turistas, levando à depredação ambiental, a inexistência de ações integradas de marketing, principalmente ocasionada pela falta de investimentos do setor público e privado em estratégias de marketing, ou mesmo em pesquisas que visem identificar o perfil do turista da localidade, o fluxo turístico recebido, dentre outros dados vitais para o desenvolvimento do turismo.

Estudos nesta seara podem ser pontuados pelos trabalhos de Dinan e Sargeant (2000) e dos recentes artigos escritos por Jamrozy (2007), Curiel e López (2009), Quian (2010) que discutem a importância do planejamento das atividades de comercialização dos destinos com o foco na sustentabilidade dos mesmos. Para os autores qualquer plano de marketing turístico deve incorporar a sustentabilidade como referência básica no desenvolvimento de suas estratégias de planejamento da atividade turística, como forma de minimizar os impactos da atividade sobre os destinos "explorados", de modo que o planejamento com foco na sustentabilidade seja um atributo que permita diferenciar os destinos concorrentes.

O objetivo do marketing turístico não é só promover o turismo regional e os outros setores de desenvolvimento econômico, mas também é concentrar-se na melhoria da eficiência cultural, ecológica e de outras áreas, porque os beneficiários da comercialização de produtos turísticos são áreas inteiras do destino (QUIAN, 2010). O marketing turístico corretamente aplicado e direcionado torna-se uma importante ferramenta na estruturação e exploração do turismo e da região vocacionada.

E para ser direcionado é necessário que o Estado, as instituições cooperativas e as empresas individuais, que são as responsáveis pela gestão do marketing, forneçam a estrutura e os serviços turísticos (alojamento, alimentação, transporte, estradas, aeroportos, água, energia...) para que a atividade possa acontecer, trabalhando de forma integrada entre si (RUSCHMANN, 1995; QUIAN, 2010).

Sendo assim, entendendo o trade turístico como o conjunto de instituições público-privadas direta ou indiretamente relacionadas ao turismo, nota-se a predominância dessas organizações nos processos de implantação das estratégias de marketing turístico. 
Com a introdução das novas técnicas de marketing na atividade turística, é preciso que seja alterado o enfoque da comercialização do turismo, deixando-se de "olhar para dentro" (ou seja, apenas ao atrativo turístico) e passando a observar ao redor, ou seja, observar o turista, suas características e desejos, e mais, fazer com que este crie uma experiência única e inesquecível que o faça voltar ao destino.

Em recente estudo Prebensen e Foss (2011) apresentaram os conceitos de coping, estratégias comportamentais e cognitivas utilizadas para administrar situações estressantes e negativas e co-creating, é um construto teórico que reflete o consumidor como tendo parte ativa da produção da experiência vivida, como uma nova tendência da atividade turística. $\mathrm{O}$ aspecto mais importante hoje, no setor de turismo, é saber fazer o consumidor participar e se engajar na produção de seu próprio bem estar, na medida em que os turistas se tornam responsáveis diretos pela produção de suas experiências.

Assim, é importante ressaltar que não apenas pelo seu potencial que novos destinos surgiram, como Austrália, Nova Zelândia, África do Sul e outros, mas graças a minimalistas planos de marketing, com enfoque no consumidor e desenvolvidos por profissionais qualificados. Ao mesmo tempo, a ausência de um plano de marketing adequado levou outros destinos a cair em desuso e ficar "fora de moda", como é o exemplo de Cancun. Comprovando dessa forma que o planejamento turístico e o plano de marketing são ferramentas que garantirão um ápice mais prolongado dos destinos turísticos (REAL, 2006).

Portanto, com base nas idéias apresentadas e no contexto esmiuçado, surge o Plano Operacional de Comercialização do Destino Bonito/MS como estratégia relevante para o planejamento da atividade turística no locus em questão.

\subsection{O Marketing do destino Bonito/MS}

Elaborado em 2006, o Plano Operacional de Comercialização do destino Bonito-MS 20062008, foi promovido pela Prefeitura Municipal de Bonito-MS juntamente com o Conselho Municipal de Turismo de Bonito-MS (COMTUR), apoiado pelo SEBRAE/MS e executado 
pela Fundação de Estudos e Pesquisas Socioeconômicas (FEPESE) da Universidade Federal de Santa Catarina (UFSC), vencedora da carta convite para a elaboração do plano.

A proposta do plano era, num prazo máximo de 24 meses, promover a "venda" e posterior alavancagem do turismo em Bonito frente aos mercados nacionais e internacionais do turismo, representada pelo incremento do fluxo turístico da ordem de $10 \%$ e $15 \%$ do volume dos recursos derivados da atividade setorial. Indubitavelmente uma dura missão, visto que é inerente do ser humano a curiosidade e o desejo de conhecer outros destinos, fazer novas descobertas e adquirir outras experiências a cada nova viagem.

Entre as ações propostas pelo plano destacam-se: a) Sistematização dos componentes da oferta turística local; b) Definição das linhas de produtos turísticos locais e os mercados para estes produtos; c) Definição de um programa regular de promoção turística; d) Definição dos canais de distribuição do produto e ações operacionais de suporte e incentivo à atração de fluxo turístico; e) Estabelecimento de metas de captação de fluxo turístico e de recursos financeiros necessários à implementação e operacionalização das ações programadas, além da definição dos atores sociais responsáveis pela condução das ações.

A elaboração do plano deu-se através de várias reuniões preparatórias com os atores locais representantes dos diversos órgãos envolvidos com os processos de natureza turística em Bonito, contando com grande participação da Secretaria Municipal de Turismo, Indústria e Comércio, bem como com integrantes do COMTUR.

Foram apresentadas, aos atores locais, questões orientadoras para efeito de avaliação e posteriormente socialização em encontro coletivo, que abordaram temas como a identificação dos elementos chamados "âncoras" da oferta local, que são os equipamentos e atrativos turísticos do destino, a sazonalidade presente na oferta da atividade turística, os principais mercados emissores de fluxos ao destino, as ações promocionais e comerciais empreendidas para a atração e retenção de turistas, o volume dos investimentos para a captação de fluxo turístico, e por fim, a coleta de sugestões de ordem geral e específicas para a superação das adversidades enfrentadas pelo 
destino, buscando responder a perguntas como: Por quê vender? O que vender? Quando vender? Para quem vender (onde)? Como vender? Através de que canais de distribuição?

A socialização das questões orientadoras, no caso do plano de comercialização de Bonito, aconteceu no dia 24 de maio de 2006, onde cada representante teve um tempo determinado para expor sua visão de como trabalhar as ações de "venda" do destino Bonito. Alguns pontos mencionados a serem trabalhados para a revitalização da atividade turística do destino foram: a) a articulação da cadeia produtiva local, aqui também se pode mencionar a ausência de cooperação e integração dos atores locais, que resulta em uma fragmentação também nas instâncias governamentais, seja em relação às estruturas disponíveis, ou mesmo, na disponibilidade de recursos financeiros, tecnológicos e até de capital humano qualificado; b) ausência de orçamentos para a promoção e a comercialização da oferta turística; e c) a dependência de produtos ou fornecedores específicos. Após a socialização das visões dos atores locais, o consultor deu início ao processo de elaboração do plano, objeto deste estudo.

Uma das primeiras ações emergenciais recomendadas pelo consultor para colocar o destino em posição de destaque no cenário nacional - e até mesmo internacional - foi a participação no Festival de Turismo do Mercosul, que ocorreu de 22 a 25 de junho de 2006. Através deste primeiro evento, e fazendo deste uma experiência "inicial", o objetivo era demonstrar a importância da participação de Bonito em eventos comerciais e promocionais. Além de investir em um público "disseminador" da atividade turística: os guias de turismo, os operadores atacadistas e os agentes de turismo em geral.

O plano não menciona se os resultados da participação neste "primeiro" evento foram ou não positivos. Também, no período de junho de 2006, o consultor procedeu a uma análise das principais revistas de viagem do país, e observou a inexistência de ações de divulgação do destino, até aquele momento, em revistas especializadas.

Sendo assim, prosseguiu-se a determinação de ações operacionais a serem implementadas para o sucesso do destino Bonito: a) Desenvolvimento de ações promocionais e comerciais em Mato Grosso do Sul (em cidades como Campo Grande, Dourados e Três Lagoas), em São 
Paulo (Grande São Paulo, Campinas, Ribeirão Preto, Araçatuba, Bragança Paulista, São José do Rio Preto, Bauru e Santos), no Paraná (Curitiba, Londrina, Maringá, Cascavel e Foz do Iguaçu), e no exterior (em países como o Paraguai e o Chile, em suas capitais federais); b) Elaboração de campanha promocional padronizada, incluindo peças publicitárias e materiais de apoio ao trabalho em eventos: folhetos e cartas para captação de eventos, folhetos informativos do destino para distribuição ao grande público em eventos comerciais e promocionais, pôsteres, guias digitais, camisetas, canetas, sacolas e brindes; c) Visita aos agentes de viagens atacadistas e varejistas para distribuição de material promocional e informativo sobre o destino, nas praças já mencionadas anteriormente; d) Visita aos veículos de imprensa especializados em turismo para distribuição de material promocional e informativo; e) Participações em eventos promocionais de natureza turística, como por exemplo, o Festival de Turismo do MERCOSUL, o Congresso Nacional da ABRASEL, dentre outros eventos; f) Inserção de anúncios publicitários e matérias promocionais, em média quatro vezes ao ano em revistas de turismo do Brasil, como, Viaje Mais, Próxima Viagem, TAM magazine, dentre outras, e três vezes ao ano em jornais, como Cadernos de Turismo da Folha de São Paulo, dentre outros; g) Qualificação da mão de obra; h) Realização de estudos e pesquisas de mercado. O desenvolvimento das ações propostas deveria ser iniciado a partir do segundo semestre de 2006.

\section{Método de pesquisa}

O estudo é caracterizado como uma pesquisa qualitativa, exploratória, descritiva e explicativa (CRESWELL, 2007; MARTINS; THEÓPHILO, 2007), do tipo estudo de caso, "um estudo de caso é uma investigação empírica que investiga um fenômeno contemporâneo dentro de seu contexto da vida real, especialmente quando os limites entre o fenômeno e o contexto não estão claramente definidos" (YIN, 2003:32). Para tanto foi realizada à coleta de dados primários in loco, através de entrevistas semi-estruturadas gravadas (QUEIROZ, 1991; PATTON, 2002; GIVEN, 2008). 


\subsection{Sujeitos da pesquisa e Processo de Coleta de Dados}

Os sujeitos da presente pesquisa foram os atores sociais representantes dos diversos segmentos produtivos diretamente envolvidos com os processos de organização, produção, gestão, distribuição e acompanhamento de serviços de natureza turística disponíveis em Bonito e que, também, foram envolvidos na construção e implementação do plano de comercialização de Bonito.

Sendo assim, os sujeitos das seguintes entidades foram entrevistados: Secretaria Municipal de Turismo, Indústria e Comércio, Diretoria de Turismo, Indústria e Comércio, Conselho Municipal de Turismo de Bonito (COMTUR), Poder Legislativo (Câmara dos Vereadores), Instituto Associação Bonitense de Hotelaria (ABH), Associação dos Proprietários de Atrativos Turísticos de Bonito e Região (ATRATUR), Associação Bonitense dos Proprietários de Agências de Ecoturismo (ABAETUR), Associação de Guias de Turismo de Bonito (AGTB), Cooperativa de Serviços Turísticos e Agência de Viagens e Turismo (COPERBON) e Serviço Brasileiro de Apoio às Micro e Pequenas Empresas (SEBRAE).

A coleta de dados ocorreu em julho de 2010 no destino em estudo, contudo o agendamento das entrevistas advieram de fevereiro à junho de 2010 via contato telefônico, conjuntamente com e-mail. No processo, de um total de dez entrevistados, foram realizadas pessoalmente nove entrevistas com duração média de 40 minutos cada, advindas de um roteiro semiestruturado composto de oito questões abertas (PATTON, 2002; GIVEN, 2008). Apenas uma entrevista aconteceu via e-mail, devido à indisponibilidade de agenda do entrevistado.

A técnica de coleta de dados utilizou-se de entrevistas gravadas (QUEIROZ, 1991). Deste modo, a partir dos relatos orais obtidos por meio das transcrições realizadas, partiu-se então para a análise e interpretação dos dados, onde foi utilizada a técnica de análise de conteúdo categorial, que cria "núcleos de sentido" (categorias) para análise das questões elencadas (SPANHOL, 2008; BARDIN, 2009). 
Tabela 01- Questões abordadas no Roteiro de Entrevista

\begin{tabular}{|l|l|}
\hline Questão 01 & $\begin{array}{l}\text { A sua empresa/instituição participou do processo de elaboração do Plano } \\
\text { Operacional de Comercialização do Destino Bonito-MS: 2006 a 2008? }\end{array}$ \\
\hline Questão 02 & $\begin{array}{l}\text { O Sr(a). tem conhecimento sobre a elaboração e as ações do Plano Operacional de } \\
\text { Comercialização do Destino Bonito-MS: 2006 a 2008? }\end{array}$ \\
\hline Questão 03 & $\begin{array}{l}\text { Na opinião do Sr(a), qual seria a importância do Plano para a atividade } \\
\text { turística local? }\end{array}$ \\
\hline Questão 04 & $\begin{array}{l}\text { O Sr(a). acredita que o Plano foi elaborado de acordo com as necessidades de } \\
\text { Bonito? Porque? }\end{array}$ \\
\hline Questão 05 & Na opinião do Sr(a). o Plano deixou de contemplar algo importante? O que? \\
\hline Questão 06 & $\begin{array}{l}\text { Quais ações já foram implantadas para fomentar os objetivos do Plano? Se há } \\
\text { ações que não foram implantadas, porque não? }\end{array}$ \\
\hline Questão 07 & $\begin{array}{l}\text { O Sr(a). acha que a forma em que o município está sendo divulgado alcança os } \\
\text { objetivos propostos pelo Plano? }\end{array}$ \\
\hline Questão 08 & \begin{tabular}{l} 
O que ainda pode ser feito para o desenvolvimento do destino Bonito? \\
\hline
\end{tabular} \\
\hline
\end{tabular}

De acordo com Bardin (2009: 33 e 40), “a análise de conteúdo é um conjunto de técnicas de análise das comunicações [...] que utiliza procedimentos sistemáticos e objetivos de descrição do conteúdo das mensagens". Para a autora a função da análise de conteúdo é enriquecer a busca pela exploração da mensagem, muitas vezes contida nas "entrelinhas" dos métodos de coleta de dados, que aqui foram os relatos orais obtidos por meio das entrevistas.

É importante mencionar que os sujeitos entrevistados não foram personificados, de forma a manter suas identidades preservadas. Cada entrevista foi lida e relida várias vezes para possibilitar uma análise em profundidade. Em seguida criou-se um levantamento dos "núcleos de sentido", ou seja, das essências dos relatos orais obtidos, sem perder de vista o contexto mais amplo da inserção da entrevista como o da situação em que ela ocorreu (SPANHOL, 2008).

Baseando-se no estudo de Spanhol (2008), este trabalho utilizou a regra da freqüência relativa, cujo objetivo é descrever o número de respostas mostrando as contagens e porcentagens associadas com cada valor de uma variável (HAIR JR et al, 2005), método utilizado por considerá-lo pertinente na caracterização da ênfase e da avaliação dos temas, 
porém lembrando que se trata de um estudo qualitativo. Os "núcleos do sentido" foram obtidos através de recortes dos relatos orais na íntegra. Agrupando e reagrupando os recortes, chegou-se às categorias, reveladoras do sentido que os relatos têm para justificar o fenômeno em estudo.

\section{Resultados e Discussões}

Aos sujeitos da pesquisa inicialmente indagou-se a importância do Plano de Comercialização para a atividade turística local, duas categorias aparecem como as mais freqüentes: a importância do plano para a "venda" do destino e a importância para o "direcionamento" do destino.

A categoria "importante/venda" engloba aproximadamente $44 \%$ dos sujeitos. Para eles, "o plano é muito importante na consolidação do destino como ícone brasileiro no ecoturismo nacional e internacional". Contudo, é interessante pontuar que há ausência de especialistas, ou mesmo de profissionais, voltados à área de marketing no destino em estudo, o que demonstra a fragilidade do território frente às ações de "venda" no mercado.

$\mathrm{Na}$ categoria "importante/direcionamento" inclui-se aproximadamente $33 \%$ dos relatos que mencionaram a importância do plano como norteador das ações do destino, "se não tivesse esse foco as coisas dispersariam, cada um ficaria do seu modo, da sua maneira”. Há ainda pouco mais de $11 \%$ que classificaram o plano como "importante/estratégico". Para eles, é "em cima do plano de marketing que você monta sua estratégia de planejamento e execução de ações".

A categoria que considerou o plano como "não-importante" foi representada por apenas $11 \%$ dos sujeitos. Porém, o que deve ser observado é que o sujeito em questão não julgou a ferramenta do plano de marketing para um destino como não-importante, e sim, exclusivamente, o plano de comercialização elaborado em Bonito no ano de 2006. Para o 
mesmo, trata-se de um "plano desatualizado e fora da realidade de Bonito". O que nos remete para a próxima questão.

A segunda indagação constante na pesquisa procurou compreender se o plano, na visão dos entrevistados, foi elaborado de acordo com as necessidades do destino Bonito, em 2006.

Novamente, não mais que $44 \%$ dos sujeitos acreditam que o plano foi elaborado de acordo com as necessidades de Bonito na época (período de 2006 a 2008). "Na época sim, por isso que nós precisamos refazer agora né [...] há um tempo atrás [...] nós estávamos avaliando trazer o turista mais nacional, hoje nós já estamos com outra visão, que é abranger fora”.

Para algo em torno de $22 \%$ dos sujeitos o plano é deveras acadêmico, uma "mera compilação do que se fala em reuniões, do que já se sabia"; logo não deu norte nenhum para os sujeitos, "de difícil implantação na prática, já nasceu um pouco obsoleto". Ainda, os mesmos sujeitos insistem na afirmação de que este não é um plano de marketing e sim de comercialização de destinos; para os mesmos há diferença entre essas duas abordagens. Contudo, essa questão não será abordada neste estudo, por necessitar de aprofundamento que não procede com o mesmo, servindo como objeto de pesquisas futuras.

Também foi indagado se o plano havia deixado de contemplar alguma ação importante para atender as necessidades do destino frente à sua comercialização. Dos sujeitos investigados, cerca de 56\% acreditam que o plano deixou de contemplar alguma ação importante, 22\% acreditam que não e outros $22 \%$ não souberam responder.

Como forma de exemplificar tal questão, nota-se que a deficiência no transporte é apontada por $56 \%$ dos sujeitos como um problema importante que o plano deixou de abordar. Sabe-se que hoje o transporte é o principal gargalo para a atividade turística de Bonito; não há leis que possibilitem e incentivem a concorrência de empresas de transporte da capital, e de outros locais, no destino.

Outra grande deficiência não abordada pelo plano é a imagem de Bonito no mercado local, regional e nacional, de ser um destino 'caro'. Nesse ínterim, 56\% dos sujeitos mencionam 
este fato como umas das grandes falhas do plano de comercialização elaborado em 2006. "Nós também estamos querendo desmistificar uma máxima que colocaram [...] pelos sulmato-grossenses de que Bonito é ‘caro'. Bonito não é caro, Bonito é mal vendido”.

Os sujeitos analisados mencionam o fato de Bonito ser um destino mal vendido no mercado, podendo atribuir esta imagem negativa tanto a falta de divulgação, através de recursos como a promoção, do mix de marketing, como também ao fato da má qualificação da mão de obra local, que por não estar preparada para atender o turista, acaba cometendo erros que geram a perda de fluxo turístico no destino.

Outra indagação proposta aos sujeitos da pesquisa buscou compreender quais ações já foram implementadas para fomentar os objetivos do Plano; ações essas descritas anteriormente neste estudo e categorizadas como 'diversas', 'pouca/nenhuma' ou 'não sabe'.

A categoria 'diversas', que engloba $44 \%$ dos sujeitos, expõe que as ações promocionais e comerciais propostas pelo plano, como, por exemplo, a realização de inserção em revistas, a participação em feiras, congressos e eventos, a qualificação e requalificação da oferta de equipamentos, dentre outras, foram implementadas.

Enquanto a categoria 'pouca/nenhuma', 33\% acredita que quase nenhuma ação do plano foi implementada, apenas investimentos em 'atrair' ao destino jornalistas, personalidades, artistas, autoridades, que colocam Bonito em mídia espontânea.

O relato acima faz menção à importância, cada vez maior, da mídia espontânea nas ações de divulgação do destino. Pouco mais de $44 \%$ dos entrevistados manifestam a crescente inserção de mídia espontânea na promoção do destino; mídia esta não contemplada pelo plano, lembrando que esta mesma mídia foi a responsável pelo despertar da atividade turística do destino no ano de 1993, e que desde então, constata-se como grande impulsionadora da atração de fluxo turístico para a região.

Em suma, são duas correntes: uma em "favor" do plano, que acredita que ele mudou ou mudará ainda a realidade do destino e outra que parece ser "contra" este fato, e que atribui o 
sucesso do destino a ações que já vinham sendo realizadas, muito antes da elaboração deste plano, como por exemplo, divulgação em revistas, participação em feiras, mídia espontânea, dentre outros.

Mais da metade dos sujeitos entrevistados, 67\% do total, não acreditam que o plano possa gerar alguma contribuição para a mudança do destino Bonito. "O plano não trouxe nada de inovador para nós". Enquanto 11\% vislumbram a perspectiva de que o plano possa contribuir para o desenvolvimento e a 'venda' do destino no mercado regional, nacional e internacional.

Com a descrença observada faz-se necessário uma reflexão. Quais os fatores que influenciaram a implementação do plano? Visto que, pelos relatos coletados, parece que o plano não somou muitas contribuições ao destino. Ademais, quais outros fatores que influenciaram a elaboração do plano e que, de certo modo, são falhas estruturais de sua elaboração? Sugere-se este questionamento para estudos futuros.

Por fim, faz-se necessário pontuar que o número de entrevistados que não tem conhecimento das ações do plano soma $20 \%$, sem dúvida um índice alto quando analisado os sujeitos da pesquisa, representantes dos diversos segmentos produtivos diretamente envolvidos com os processos de organização, produção, gestão, distribuição e acompanhamento de serviços de natureza turística disponíveis em Bonito e que, também, foram envolvidos na construção e implementação do plano de comercialização de Bonito.

Outro ponto que deve ser observado é que, tomando como base o ano de elaboração do plano (2006), o turismo continuou em queda nos anos que prosseguiram à elaboração do mesmo, queda de pouco menos de $2 \%$ em 2007 e ainda quase $13 \%$ no ano de 2008 (ISSQN-BONITO, entre 1996 e 2010).

Já em relação ao ano de 2009, quando comparado ao ano anterior, houve um acréscimo em $56 \%$ de fluxo turístico. Se comparado ao ano de 2006, quando houve a necessidade de criação do Plano de Comercialização do destino Bonito-MS para regularizar o fluxo turístico que 
desde 2004 se apresentava em decréscimo, o ano de 2009 ainda apresenta uma taxa positiva da ordem de quase 34\% (ISSQN-BONITO, entre 1996 e 2010).

O ano de 2009 é o primeiro ano em que o turismo em Bonito, após quatro anos consecutivos em queda, retomou sua participação na atração de fluxo turístico. Quando comparado a 2003, que até então era o ano que mais havia atraído turistas na história de Bonito, o ano de 2009 apresenta um acréscimo da ordem de pouco menos de $17 \%$, um recorde no comportamento do fluxo turístico em Bonito (ISSQN-BONITO, entre 1996 e 2010).

\section{Considerações Finais}

Bonito destaca-se como um dos 65 destinos indutores do turismo do Brasil, sendo pólo de atração de turistas nacionais e internacionais (MINISTÉRIO DO TURISMO, 2009). Localizado em uma região de natureza rica e peculiar, o destino desenvolveu-se no segmento turístico ao longo da década de 90, tratando-se de uma atividade ainda recente e jovem, mas que se apresenta como uma das principais atividades geradoras de emprego e renda para a região.

Diante do declínio na movimentação turística em Bonito nos anos recentes, foi elaborado um plano de marketing com o intuito de 'vender' o destino no mercado interno e externo, promovendo a interface entre as ferramentas do marketing e o turismo. Para entender a eficiência do plano na promoção de ações de comercialização do destino foram realizadas entrevistas junto ao trade turístico.

Contudo, apesar de $88 \%$ dos sujeitos da pesquisa considerarem o plano de comercialização importante para as estratégias de venda e direcionamento do destino, aproximadamente $56 \%$ dos mesmos apontam falhas estruturais no plano, tais como: a não segmentação do públicoalvo, a não diferenciação entre as ferramentas de marketing e de comercialização (para os mesmos há diferenças entre elas, não abordadas no plano), a não apresentação dos gargalos da 
atividade turística local, como exemplo, o setor do transporte, e ainda, o não detalhamento das fontes financiadoras de recursos, que seria a fase orçamental para a implementação do plano.

O que deve ser elucidado é que o plano não detalha suas ações com a abrangência necessária, parecendo um grande 'esboço' ou 'brainstorm' de idéias. Faz-se então preciso uma revisão e atualização de modo a incorporar as etapas necessárias que o plano de 2006 deixou de contemplar.

O destino em pauta apresenta problemas de ordem estruturais, na operação comercial de seus componentes da oferta. No entanto, a busca de soluções para os problemas de ordem estrutural passa, primeiramente, por ações de qualificação profissional em sintonia com as macro-políticas de fomento do turismo nacional, ações que podem ser incorporadas como elementos de vantagem competitiva e alavancagem do destino frente às mídias impressas e eletrônicas nacionais.

Talvez um dos maiores problemas do município em tela seja o fato de ser um destino desconhecido pelos próprios habitantes do Estado e quiçá do próprio município. O destino é estigmatizado como sendo 'caro' e não há políticas públicas de fomento a atividade turística para os sul-mato-grossenses.

Faz-se necessário, cada vez mais pontualmente, que se criem políticas de promoção turística para a comercialização do destino para os sul-mato-grossenses, que devem ser os primeiros propagadores e promotores da atividade turística do Estado, e conseqüentemente, da geração de emprego e renda que a atividade turística acarreta para a região de Bonito e da Serra da Bodoquena.

Ao término deste estudo chega-se a conclusão da importância da ferramenta do marketing para a divulgação dos destinos e atração de fluxo turístico, responsável pela geração e manutenção de emprego e renda no destino. O fato é que não existe substituto para a experiência real proporcionada pelo turismo; ele é e continuará sendo um dos maiores setores do mundo. Por mais que existam novas tecnologias que nos proporcionem 'conhecer' outros 
destinos virtualmente ou ainda por maior que seja o número de atividades de lazer possíveis de serem realizadas no conforto de nossas salas, a maioria de nós continuará se levantando de suas poltronas na busca de novas experiências a serem vivenciadas (NAISBITT, 1994).

Trata-se este de um estudo inicial de um fenômeno tão vasto e complexo, o turismo e suas ferramentas mercadológicas. A ele pretendemos voltar, conforme já foi tencionado, em trabalhos futuros. Assim espera-se que este trabalho tenha gerado alguma contribuição para o sucesso do destino turístico de Bonito, frente ao mercado nacional e internacional do turismo, visto que à luz da academia este trabalho surge como uma forma de sanar a limitação de produção sobre a temática.

\section{Referências}

ALMEIDA, N.P. Segmentação do turismo no pantanal sul-mato-grossense. Dissertação (Mestrado em Desenvolvimento Local). Campo Grande: UCDB, 2002, 143p.

AMA- American Marketing Association. 2007. Definition of marketing. Disponível em: $<$ http://www.marketingpower.com/AboutAMA/Pages/DefinitionofMarketing.aspx $>$. Acesso em: 29 ago. 2010.

ANDRADE, J.V. Turismo: Fundamentos e dimensões. 4aed. São Paulo: Editora Ática, 1998.

ATRATUR- Associação de atrativos turísticos de Bonito e região. O sistema turístico de Bonito-MS, 2010. Disponível em: <http://www.atrativosbonito.com.br/institucional.php?cod=104>. Acesso em: 13 abr.2010.

BALANZÁ, M.I.; NADAL, M.C. Marketing e comercialização de produtos turísticos. São Paulo: Pioneira Thomson Learning, 2003.

BARDIN, L. Análise de conteúdo. $5^{\mathrm{a}}$ ed. Portugal: Edições 70, 2009.

CHURCHILL JR, G.A.; PETER, J.P. Marketing: criando valor para o cliente. São Paulo: Saraiva, 2007.

COOPER, C. et al. Turismo princípios e práticas. $3^{\mathrm{a}}$ ed. Porto Alegre: Bookman, 2007.

CRESWELL, J.W. Qualitative inquiry and research design: Choosing among five approaches. $2^{\mathrm{a}}$ ed. United States of America: Sage Publications, 2007. 
CORIOLANO, L.N.M.T. Do local ao global- o turismo litorâneo cearense. $3^{\mathrm{a} e d . ~ C a m p i n a s: ~ P a p i r u s, ~}$ 2002.

CURIEL, J.E.; LÓPEZ, A.L. Una aproximación al marketing turístico sostenible desde la planificación estratégica. Observatorio Medioambiental, v.12, 2009, p. 37-47.

DIAS, R; CASSAR, M. Fundamentos do marketing turístico. São Paulo: Pearson Prentice Hall, 2005.

DINAN, C.; SARGEANT, A. Social marketing and sustainable tourism- is there a match? International journal of tourism research, 2000, p.1-14.

DROUlERS, M.; MILANI, C. R. S. Desenvolvimento local e turismo em Tarrafal - Cabo Verde. Paris: UNESCO, 2002.

ESCRITÓRIO TÉCNICO DE ESTUDOS ECONÔMICOS DO NORDESTE - ETENE. Panorama do Setor Turístico. Ano 4, nº 18, set. 2010.

FELTON, A.P. Making the marketing concept work. Harvard Business Review, n.37, July/Aug. 1959, p. 55-65.

FERRELL, O.C et al. Marketing Strategy. Orlando: The Dryden Press, 1998.

GIVEN, L.M. The Sage encyclopedia of qualitative research methods. United States of America: Sage Publications, 2008.

HAIR JR., J. H. et al. Fundamentos de métodos de pesquisa em administração. Porto Alegre: Bookman, 2005.

IBGE - INSTITUTO BRASILEIRO DE GEOGRAFIA E ESTATÍSTICA. Economia do turismo, $2005 . \quad$ Disponível em: $<$ http://www.ibge.gov.br/home/estatistica/economia/industria/economia_turismo/2000_2005/comentar ios.pdf>. Acesso em: 17 jan. 2011.

ISSQN- BONITO. Total de visitantes em Bonito. Programa de gerenciamento do ISSQN e Estatística do turismo em Bonito-MS. Bonito: 1996 a 2010.

JAMROZY, U. Marketing of tourism: a paradigm shift toward sustainability. International Journal of Culture, Tourism and Hospitality Research, v. 01, n.02, 2007, p. 117-130.

KEITH, R.J. The marketing revolution. Journal of Marketing, v. 24, n.3, winter 1960, p.35-38.

KOTler, P; ARMStrong, G. Principios de marketing. 12aed. São Paulo: Pearson Prentice Hall, 2007.

KUAZAQUI, E. Marketing Turístico e de Hospitalidade. São Paulo: Makron Books, 2000.

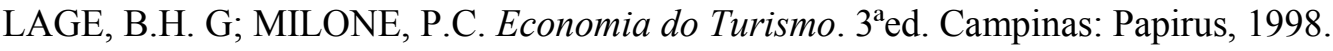

LAS CASAS, A.L. Marketing - Conceitos, Exercícios e Casos. 4ªed. São Paulo: Atlas, 1997. 
LITVIN, S.W. Marketing visitor attractions: a segmentation study. International Journal of tourism research, 2007, p. 9-19.

LOHMANN, G; NETTO, A. P. Teoria do turismo: conceitos, modelos e sistemas. São Paulo: Aleph, 2008.

MARTINS, G.A; THEÓPHILO, C.R. Metodologia da investigação cientifica para ciências sociais aplicadas. São Paulo: Atlas, 2007.

MENDONÇA, M. C. A. Gestão integrada do turismo no espaço rural. 2006. 290 f. Tese (Doutorado em Engenharia de Produção)- Universidade Federal de São Carlos, São Carlos, 2006.

MIDDLETON, V. Marketing in travel and tourism. $3^{\mathrm{a}}$ ed. England: Butterworth Heinemann, 2001.

MIDDLETON, V. Marketing de turismo: teoria e prática. $3^{\mathrm{a}}$ ed. Rio de Janeiro: Elsevier, 2002.

MINISTÉRIO DO TURISMO. Estudo de competitividade dos 65 destinos indutores do desenvolvimento turístico regional. Relatório Brasil 2009. Brasília: Ministério do turismo, 2009.

Disponível

em:<http://200.143.12.93/export/sites/default/dadosefatos/outros_estudos/downloads_outrosestudos/E studo_Competitividade_2009.pdf $>$. Acesso em: 22 set. 2010.

MOTA, K. C. N. Marketing Turístico- promovendo uma atividade sazonal. São Paulo: Editora Atlas, 2001.

NAISBITT, J. Paradoxo global. Tradução: Ivo Korytowski. Rio de Janeiro: Campus; São Paulo:

Publifolha, 1999.

OMT- Organização Mundial do Turismo. Guia de desenvolvimento do turismo sustentável. Tradução: Sandra Netz. Porto Alegre: Bookman, 2003.

PATTON, M.Q. Qualitative Research \& Evoluation Methods. $3^{\mathrm{a}}$ ed. United States of America: Sage Publications, 2002.

PETROCCHI, M. Marketing para destinos turísticos. São Paulo: Futura, 2004.

PREBENSEN, N.K.; FOSS, L. Coping and Co Creating in Tourism Experiences. International Journal of Tourism Research, 2011, p. 54-67.

PREFEITURA MUNICIPAL DE BONITO. Plano operacional de comercialização do destino BonitoMS: 2006 a 2008. Bonito: 2006. Mensagem recebida por <marianamonfort@gmail.com> em 01 mar. 2010.

QUIAN, S. Research on behaviors of government's tourism marketing. UTMS Journal of economics, v.01, n. 01, p. 99-106, 2010.

QUEIROZ, M. I. P. Variações sobre a técnica de gravador no registro da informação viva. São Paulo: T.A Queiroz, 1991. 
REAL, D.C. Análise dos indicadores de marketing da promoção turística internacional em MS. 2006.158 f. Trabalho de conclusão de curso (Graduação em Turismo com ênfase em Turismo Ambiental e Hotelaria) - Universidade para o Desenvolvimento do Estado e da Região do Pantanal UNIDERP, Campo Grande, 2006.

RUSCHMANN, D. Marketing turístico - um enfoque promocional. 2a ed. Campinas: Papirus, 1995.

SANTANA, G. G. Avaliação da adequação e eficácia de programas de marketing de destinos turísticos: uma análise de Balneário Camboriú- Santa Catarina, Brasil. Turismo em análise, São Paulo, v.19, n.3, dez. 2008.

SEBRAE- Serviço Brasileiro de Apoio às Micro e Pequenas empresas. Presidente do Sebrae aposta em plano de marketing para Bonito (MS), 2006. Disponível em: $<\mathrm{http}: / /$ asn.interjornal.com.br/noticia.kmf?canal $=212 \& \operatorname{cod}=4263378 \&$ indice $=80>$. Acesso em: $22 \mathrm{fev}$. 2010 .

SPANHOL, C. P. Intergeracionalidade na escolha de alimentos. 2008. Dissertação (Mestrado em Agronegócios) - Universidade Federal de Mato Grosso do Sul- UFMS, Campo Grande, 2008.

TOALDO, A. M. M.; LUCE, F.B. Estratégia de marketing: contribuições para a teoria em marketing, RAE, São Paulo, v.46, n.4, out/dez 2006. Disponível em: < http://www16.fgv.br/rae/redirect.cfm?ID=3826>. Acesso em: 26 ago. 2010.

VAZ, G. N. Marketing turístico receptivo e emissivo- um roteiro estratégico para projetos mercadológicos públicos e privados. São Paulo: Ed. Guazzelli, 1999.

VIGNATI, F. Gestão de destinos turísticos - Como atrair pessoas para pólos, cidades e países. Rio de Janeiro: Ed. SENAC Rio, 2008.

WESTWOOD, J. O plano de marketing-Como elaborar um plano de marketing competente, objetivo e vencedor. São Paulo: Makron Books, 1991.

WTO - WORLD TOURISM ORGANIZATION. World Tourism Barometer. Madri, v. 7, n. 2, Jun. 2009.

WTO - WORLD TOURISM ORGANIZATION. International Tourism 2010: Multi-speed recovery. Disponível em: <http://www.world-tourism.org/facts/menu.html>. Acesso em 17 jan. 2011.

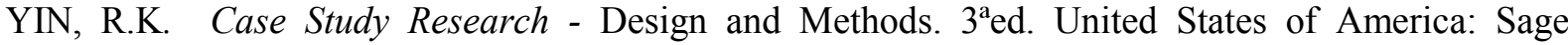
Publications, 2003.

Recebido em: 28/02/2011 ( $1^{\text {a }}$ versão) $25 / 04 / 2011$ ( $2^{a}$ versão)

Aprovado em: 11/07/2011 